\title{
Training the female competitor: physiological aspects of fitness
}

\author{
Y. Koutedakis MA, PhD and N. C. Craig Sharp* PhD, MRCVS, FIBiol \\ School of Health Sciences, Wolverhampton Polytechnic, Wolverhampton WV1 1DJ, UK and \\ *The British Olympic Medical Centre, Northwick Park Hospital, Harrow, UK
}

\begin{abstract}
No single parameter can disclose the state of physical fitness of elite female competitors. For such individuals, fitness is a composite which varies markedly from one sport to another. It contains aspects of body size and composition, aerobic (general endurance) and anaerobic (local muscular endurance/speed) metabolism, together with aspects of muscle strength. Elements of joint mobility and dynamic balance may also be included. Thus, by obtaining regular laboratory data on key physiological parameters, areas of relative weakness may be detected and trained. In the current context, various components of fitness, their physiological assessment, and some comparative data are discussed.
\end{abstract}

\section{Body size and body composition/body fat}

The body sizes of boys and girls are approximately identical until the age of 9-10 years. At this point, the earlier adolescent growth spurt of girls causes them to forge ahead, with most of the boys catching up by the age of 13, when their growth begins to take them beyond the girls by a factor of $8-10 \%$ in most size dimensions. Differences in the relative width of shoulders, thorax and hips result in a lower centre of gravity in women, with possible implications for a better sense of balance.

During the time of the growth spurt, boys show a ten-fold increase in the anabolic hormones, important for muscle development, while in girls these increases are considerably less. During this time, bone and muscle is more susceptible to damage, both by heavy loading in terms of force, and by too many repetitions of the same movement pattern.

At the end of the growth spurt, the 'average' non-athletic European woman of 20-30 years of age has a skeleton of $3.4 \mathrm{~kg}$ dry weight, $4.0-4.5$ litres of blood, with $50 \%$ of body-weight as water and $28-32 \%$ body fat. The corresponding values for men are $5.0 \mathrm{~kg}$ of skeleton dry weight, $5.0-6.0$ litres of blood, $60 \%$ water and $18-23 \%$ body fat. The average female competitor may carry approximately twice as

Address for correspondence: Dr Y. Koutedakis

(C) 1991 Butterworth-Heinemann Ltd 0306-3674/91/040188-03 much fat as her male counterpart, relative to her own body-weight. From a coaching viewpoint, increased body fat in women acts as a weight handicap, imposing greater inertia on limb segments which probably have less muscle to overcome it.

Many sportswomen have body fat in the range of $11-16 \%$. Attempts to reduce the amount of fat in women further may lead to two medical complications which coaches have to bear in mind: sports amenorrhoea and anorexia nervosa. Sports amenorrhoea, or absence of periods, is associated with low levels of the female hormone oestrogen, and is related to bone calcium losses. The calcium loss may cause osteoporosis, or bone mineral loss, which increases the likelihood of stress fractures.

Whether sports amenorrhoea only results from increased training or a combination of factors, including psychological stresses, is not yet clear. However, strenuous physical efforts made by women may cause increases in beta-endorphins, and the other hormones (melatonin, prolactin and ACTH) which are associated with delays in sexual maturation and impairment of the reproductive cycle in animal experimental work.

\section{Aerobic fitness}

A popular exercise laboratory test is the monitoring of aerobic fitness by maximal oxygen intake tests. However, sporting success in elite endurance female competitors does not depend only on aerobic parameters. Aspects related to mechanical efficiency due to female anatomical characteristics (e.g. broader hips, bent arms) are also important.

By the end of a maximal aerobic (endurance) test, the minute ventilation (the volume of air in litres breathed in and out per minute) may increase 10-15-fold for both men and women. We have recently measured maximal minute ventilation values of above 240 and 170 litres $\mathrm{min}^{-1}$ in elite male and female rowers respectively. There is little difference between the two sexes in maximal breathing frequency. From a resting 12 breaths $\min ^{-1}$, the respiratory rate may rise six-fold at the final stages of a maximal aerobic test. Values of maximal oxygen intake $\left(\dot{V}_{\mathrm{O}_{2}}, \max \right)$, which correlate reasonably well with performance in endurance events, may rise to 
approximately $78 \mathrm{ml} \mathrm{kg}^{-1} \mathrm{~min}^{-1}$ in female international long-distance runners. Their male counterparts are able to produce values of $85-92 \mathrm{ml} \mathrm{kg}^{-1} \mathrm{~min}^{-1}$.

The main explanation behind the lower $\dot{V} \mathrm{O}_{2 \max }$ values demonstrated by women may include: women's heart volume is $15-20 \%$ less than that of men; women have haemoglobin levels of $12-14 \mathrm{~g}$ $100 \mathrm{ml}^{-1}$ compared with $14-16 \mathrm{~g} 100 \mathrm{ml}^{-1}$ in men; $42 \%$ of women's blood volume is red cells compared with $47 \%$ for men; and women's blood comprises only $65 \mathrm{ml} \mathrm{kg}^{-1}$ body-weight compared with $75 \mathrm{ml} \mathrm{kg}^{-1}$ body-weight in men. These points indicate that women are disadvantaged in transporting oxygen to working muscle. However, in terms of training for aerobic fitness, no differences have been identified between men and women.

\section{Anaerobic fitness}

Anaerobic fitness is the ability to produce energy via processes that do not require oxygen, and applies to sporting activities of short duration but high intensity. Strictly speaking, measurements of anaerobic fitness are less satisfactory, mainly because it is too difficult to partition what is aerobic and what is anaerobic in terms of mid-length (10-60 s) bursts of energy. Power output measures and lactic acid analyses are two useful methods used to assess anaerobic fitness.

\section{Anaerobic power output}

This may be measured by variants of the Wingate test, in which the competitor cranks maximally against a resistance which varies according to age, sex and whether the legs or arms are being tested ${ }^{1}$. The information received from the Wingate test consists of peak power, time to peak power, fatigue rate and total work. Often, a recovery index is assessed from, for example, two successive 15-s or 30-s tests, 4-5 min apart, with the total work of the second test being expressed as a percentage of that of the initial test.

For throwers one looks for high peak power; for sprinters a fast time to peak is important; for rowers a low rate of fatigue; for squash players a particularly high recovery index. Female competitors from different sports normally show lower absolute and relative peak power outputs than their male counter- parts. However, there is virtually no difference in time to peak power or in recovery index between the sexes.

\section{Lactic acid measurements}

Lactic acid is a product of the anaerobic energy production mechanism and is often measured in blood samples taken from a fingertip or ear lobe, 3-5 min after short but intensive exercise. Low maximal lactic acid values may either reflect low anaerobic capabilities, or an increased capacity of the body to buffer, utilize or remove large amounts of lactic acid. The opposite may be assumed in the case of high lactic acid values.

Female elite competitors normally demonstrate lower absolute maximal lactic acid levels than their male counterparts. Female rowers, canoeists and fencers have shown maximal lactic acid values of 14, 9 and $5 \mathrm{mmoll}^{-1}$ respectively, with the equivalent values for men being 19,12 and $7 \mathrm{mmoll}^{-1}$ of blood.

\section{Strength}

The narrower shoulders of the female competitor give her considerably less muscle on the back and chest which, together with the shorter proportional length of women's arms, leads to a relative imbalance of upper and lower body strength. Women and men approximate much more closely in lower body strength compared with that of their upper body. In sports such as rowing, these differences become particularly obvious. After maturity, muscle of both sexes is similar in terms of strength per unit of cross-sectional area ${ }^{2}$.

Mechanical dynamometers, strain gauges, and computerized equipment are used to obtain data regarding the tension developed by various muscle groups in elite competitors. Female throwers and male rugby players, for example, demonstrate higher isokinetic peak torque values than their counterparts who participate in different sports (Table 1).

These findings may be accounted for partly by different training programmes and partly by different muscle fibre profiles. Indeed, numerous reports have indicated that power event elite competitors have higher proportions of fast twitch (FT) fibres in, for example, the vastus lateralis than endurance event

Table 1. Mean isokinetic concentric peak torque values $(\mathrm{N} \mathrm{m})$ for shoulder and knee flexion/extension in female and male competitors

\begin{tabular}{|c|c|c|c|c|c|c|}
\hline & \multicolumn{3}{|c|}{ Women } & \multicolumn{3}{|c|}{ Men } \\
\hline & Rowing & Squash & Throwing & Rugby & Wrestling & Kayaking \\
\hline \multicolumn{7}{|c|}{ Shoulder $\left(70^{\circ} \mathrm{s}^{-1}\right)$} \\
\hline \multirow[t]{2}{*}{ Extension } & $\begin{array}{l}42 \\
58\end{array}$ & $\begin{array}{l}38 \\
51\end{array}$ & $\begin{array}{l}66 \\
78\end{array}$ & $\begin{array}{r}88 \\
142\end{array}$ & $\begin{array}{r}83 \\
131\end{array}$ & $\begin{array}{r}80 \\
137\end{array}$ \\
\hline & & & & Rugby & Squash & Biathletics \\
\hline \multicolumn{7}{|l|}{ Knee $\left(60^{\circ} \mathrm{s}^{-1}\right)$} \\
\hline $\begin{array}{l}\text { Flexion } \\
\text { Extension }\end{array}$ & $\begin{array}{r}89 \\
212\end{array}$ & $\begin{array}{r}79 \\
168\end{array}$ & $\begin{array}{l}138 \\
266\end{array}$ & $\begin{array}{l}169 \\
372\end{array}$ & $\begin{array}{l}136 \\
280\end{array}$ & $\begin{array}{l}119 \\
220\end{array}$ \\
\hline
\end{tabular}


competitors. Such power event competitors may demonstrate up to $95 \%$ FT fibres which are metabolically equipped for forceful contractions that depend largely on anaerobic mechanisms for energy supply. FT fibres may also be two to four times faster and approximately $50 \%$ larger than fibres classified as slow. It should be noted here that the athlete's muscle fibre profile is determined both by genetic and environmental (training) factors ${ }^{3}$. No obvious muscle fibre profile differences have been established between men and women competing in similar events.

While muscle size has been associated with muscular strength, hypertrophy (the increase in muscle size or bulk) has been associated with gains in strength. However, because muscular development is partly linked with plasma testosterone levels, men are capable of considerably greater gains in muscle bulk than are women. Some researchers have concluded that muscular hypertrophy in women is not a necessary consequence of strength training.

\section{Conclusion}

Ward and Whipp ${ }^{4}$ plotted the decade-by-decade improvement in the mean running velocity for both men and women for all events between $200 \mathrm{~m}$ and the marathon. It was found that the improvement rate for women is more than double that for men, reflecting both the increased numbers of women coming into sport and the proportionately greater increases in their training.

\section{References ,}

1 Koutedakis Y, Sharp NCC. A modified Wingate test for measuring anaerobic work of the upper body in junior rowers. Br J Sports Med 1986; 20: 153-6.

2 Davies CTM. Strength and mechanical properties of muscle in children and young adults. Scand J Sports Sci 1985; 7: 11-15.

3 Komi PV. The musculoskeletal system. In: Dirix A, Knuttgen HG, Tittel K, eds. The Olympic Book of Sports Medicine. Oxford: Blackwell Scientific Publishers, 1988: 15-39.

4 Ward SA, Whipp BJ. Will women outperform men in Olympic running in the twenty-first century? J Physiol 1990; 423: 24P.

\section{Errata}

Stoneham MD, Morgan NV. Stress fractures of the hip in Royal Marine recruits under training: a retrospective analysis. Br J Sports Med 1991; 25: 145-8.

The publishers wish to apologise for the accidental substitution of an incorrect address for correspondence.

Please send correspondence to:

Surgeon Commander N. V. Morgan RN, Brigade Medical Adviser, 3 Commando Brigade, Stonehouse Barracks, Plymouth, UK.
McCaw ST, Bates BT. Biomechanical implications of mild leg length inequality. Br J Sports Med 1991; 25: 10-13.

The publishers also wish to apologise for the incorrect spelling of Dr S. T. McCaw's name both in the table of contents and the article running head. 